\title{
A NARRATIVA DA MONTAGEM DO FUNK CARIOCA NO COTIDIANO ESCOLAR
}

\author{
José Carlos Teixeira Júnior
}

\begin{abstract}
RESUMO: O presente artigo tem como objetivo principal discutir a possibilidade de a narrativa da montagem do funk carioca orientar práticas educacionais mais emancipatórias. Enquanto uma prática musical da diáspora negra fortemente presente no cotidiano da escola municipal carioca de ensino fundamental em que trabalho (e de tantas outras escolas municipais, certamente), a narrativa da montagem do funk carioca abre possibilidades bastante férteis no deslocamento das relações neocoloniais que tecem a educação escolar, mais especificamente no enfrentamento da própria questáo racial. Sobretudo, pelo fato de posicionar esta mesma questão não nos limites biológicos (fenótipo), geográficos (favela) ou culturais institucionalizados (OFunk), mas sim no âmbito das chamadas práticas (musicais) cotidianas.
\end{abstract}

Palavras-chave: Educação; Cotidiano; Diáspora negra; Montagem; Funk.

\section{THE NARRATIVE OF THE CARIOCA FUNK ASSEMBLY IN THE EVERYDAY SCHOOL LIFE}

\begin{abstract}
This article aims to discuss the possibility of orienting more emancipating educational practices by the narrative of the carioca funk assembly. As a black diaspora musical practice, strongly present in the routine of the municipal elementary school in the city of Rio de Janeiro where I work (and many other local schools, certainly), the narrative of the carioca funk opens up quite fertile possibilities for the displacement of neocolonial relations that weave school education, specifically in addressing the very issue of race. This is mainly due to the fact that it does not position this question in terms of biological (phenotype), geographic (favela) or institutionalized cultural limits (funk), but within the framework of the so-called everyday (musical) practices.
\end{abstract}

Keywords: Education; Everyday life; Black diaspora; Assembly.

\footnotetext{
* Fundação de Apoio à Escola Técnica do Estado do Rio de Janeiro, Rio de Janeiro, RJ., Brasil. E-mail de contato: zeca.teixeira@yahoo.com.br..
} 


\section{LE RÉCIT DU MONTAGE DU FUNK CARIOCA AU QUOTIDIEN DES ÉCOLES}

RÉSUMÉ: Cet article vise à discuter la possibilité du récit du montage du funk guider les pratiques éducatives plus émancipatrices. En tant qu'une pratique musicale de la communauté noire fortement présente au quotidien à l'école municipale où je travaille et bien d'autres écoles locales, le récit du funk montage ouvre des possibilités très fertiles dans le déplacement des relations néocoloniales qui tissent l'enseignement scolaire, en particulier pour aborder la question de la race elle-même. Surtout pour ne pas placer cette question dans des limites biologiques (phénotype), géographique (favela) ou culturelle institutionnalisée (funk), mais dans la pratique dite musicale de tous les jours.

Mots-clés: Education; Quotidien; Communauté noire; Montage.

Percebo que a lição mais importante que a música ainda tem a nos ensinar

é que seus segredos intimos e suas regras étnicas podem ser ensinadas e aprendidas.

Paul Gilroy

\section{Introdução}

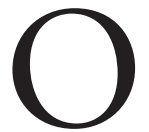

presente artigo tem como objetivo principal colocar em discussão a seguinte questão: como a montagem do funk carioca pode contribuir na orientação de práticas educacionais mais emancipatórias a partir da experiência vivênciada na Escola Municipal Compositor Luiz Gonzaga, local em que trabalho como professor de música desde meados de 2008? Trata-se de uma questão que emerge da trajetória de minha pesquisa de doutorado, um diálogo com algumas práticas musicais da diáspora negra (GILROY, 2001) ${ }^{1}$ na educação escolar, e que assume, na esteira proposta por Passos, os encontros e desencontros cotidianos como metodologia de investigação (PASSOS, 2012). Segundo esta autora,

[...] los encuentros se han sembrado en terreno fértil para pensar conceptos, provocar discusiones y alimentar la producción en el grupo. Interpretar el movimiento dialógico por el cual pasan los interlocutores y los mismos investigadores ha sido enriquecedor. 
El surgimiento de saberes, relaciones y narrativas se presenta cuando un sujeto "es afectado por el otro", hecho generador de conocimiento. (PASSOS, 2012, p. 24)

Discutir a possibilidade da montagem do funk carioca orientar práticas educacionais emancipatórias se apresenta, assim, como uma etapa nestes mais diferentes (des)encontros, "quando um sujeito [afeta e] é afetado por outro", que tecem o diálogo com as práticas musicais da diáspora negra no âmbito do cotidiano da educação escolar.

A referida escola municipal foi criada e assim nomeada pelo decreto no 9.994 de 19/02/1991, tendo iniciado suas atividades em março de 1990, ano seguinte à morte de seu patrono, o chamado Rei do Baião. Ela está localizada em Jacarepaguá (zona oeste da cidade do Rio de Janeiro), regiấo pertencente à $7^{\text {a }}$ Coordenadoria Regional de Educação (CRE) da Secretaria Municipal de Educação (SME) da Prefeitura da Cidade do Rio de Janeiro, e possui cerca de 60 professores e de 1200 alunos dos dois segmentos do ensino fundamental. A grande maioria destes alunos reside na Cidade de Deus (também conhecida como CDD), localidade bem vizinha à escola que deu nome ao primeiro romance de Paulo Lins (1997) e ao premiado filme de Fernando Meirelles (CIDADE DE DEUS, 2002), enquanto os demais alunos residem em outras tantas localidades de Jacarepaguá, como Gardênia Azul, Freguesia, Anil, Rio das Pedras, dentre outras.

A escolha desse objetivo se justifica, basicamente, pelo seguinte motivo: enquanto uma prática musical da diáspora negra (VIANNA, 1987; GILROY, 2001; ESSINGER, 2005; LOPES, 2011) fortemente presente no cotidiano da escola municipal carioca de ensino fundamental em questão (e de tantas outras escolas municipais, certamente), a prática de montagem do funk carioca $^{2}$ abre possibilidades bastante férteis no deslocamento das relações neocoloniais (SCHMIDT, $2011)^{3}$ que tecem a educação escolar, mais especificamente no enfrentamento da própria questão racial. Sobretudo, pelo fato de posicionar esta mesma questão não nos limites biológicos (fenótipo), geográficos (favela) ou culturais institucionalizados (O Funk), mas sim no âmbito das chamadas práticas (musicais) cotidianas. (CERTEAU, 1994; GILROY, 2001)

\section{Sobre as relações neocoloniais no sistema público de ensino da Prefeitura da Cidade do Rio de Janeiro}

As relaçóes neocoloniais que atravessam a rede pública municipal de ensino da Prefeitura da Cidade do Rio de Janeiro, de uma forma geral, e a referida escola municipal de ensino fundamental, de uma forma mais específica, 
estruturam alguns determinantes do presente trabalho de pesquisa. Em primeiro lugar, pela própria política educacional, meritocrática, adotada pela Secretaria de Educação. Política educacional em forte consonância com as chamadas políticas neoliberais, pautadas, conforme sintetiza Gentili, na organização pós-taylorista do trabalho, no caráter estruturalmente dualizado da sociedade e no Estado autoritário pós-keynesiano. (GENTILI, 1995)

Desde 2009, com a gestão dos atuais Prefeito e Secretária de Educação, observa-se a subalternização de professores e alunos no processo de ensino com a gradativa implementação de uma enorme e arbitrária diversidade de projetos educacionais privados. Projetos como Realfa, Acelera, Ginásio Experimental Carioca (e suas mais diversas versóes: Olímpico, Artístico, do Samba, de Novas Tecnologias Educacionais), $6^{\circ}$ ano Experimental, Discovery na Escola, Cientistas do Amanhã, Rio Criança Global, Escolas do Amanhã, dentre outros, vêm sendo contratados e geridos em pacotes por uma diversidade de organizaçóes não-governamentais, institutos e fundaçóes, como Fundação Roberto Marinho e Instituto Ayrton Senna.

$\mathrm{Na}$ total ausência do (não apenas necessário, mas fundamental, ainda que, certamente, bastante complexo) debate com as mais de 1.000 comunidades escolares que tecem o referido sistema público municipal de ensino ${ }^{4}$ quanto aos referidos gestores, classificaçóes, conteúdos e metodologias que envolvem os respectivos projetos, tanto professores como alunos têm se tornado meros instrumentos de reprodução e perpetuação daquilo que a referida Secretaria de Educação tem chamado, na esteira da educação desenvolvida no âmbito corporativo (EBOLI, 2004), de competências e habilidades.

Competências e habilidades naturalizadas, mensuradas e estimuladas por uma diversidade de avaliaçóes externas (como Prova Brasil e Prova Rio), índices (como Ideb e IdebRio), metas (como as fixadas pelo Ministério da Educação e pela Secretaria Municipal de Educação) e premiaçôes (como $14^{\circ}$ ou $15^{\circ}$ salários aos profissionais da SME quando cumprem as referidas metas), os quais ignoram por completo as mais diferentes questôes que atravessam os cotidianos das referidas comunidades escolares (como a questão racial) ao pretender posicioná-las totalmente fora de seu próprio movimento de significaçáo.

Em segundo lugar, e como um desdobramento deste primeiro argumento, por determinados e negligenciados procedimentos disciplinares fortemente presentes no cotidiano escolar. E aí, uma imagem me vem imediatamente à memória. Não consigo esquecer quando, certa vez, ao ver um aluno caminhar sozinho e de forma tranquila pelo corredor da referida escola municipal aos ritmados e bastante complexos passos de funk (mais conhecidos como duelo de passos ou batalha do passinho), eu tive a oportunidade de escutar uma professora falar em alto e bom som da porta de sua sala de aula localizada do outro lado deste mesmo corredor: "tira isso do corpo, menino!". Imediatamente, o menino olhou para ela, 
abriu um enorme sorriso e deu continuidade, de uma forma bem despreocupada e irônica, àquela sua curiosa caminhada pela escola. Em outras palavras, existe um poderoso procedimento disciplinar, capilarizado no cotidiano escolar e, portanto, de forma alguma restrita ou limitada a posiçóes específicas da estrutura educacional, seja ela professor, aluno, funcionário, direção, responsável, CRE ou mesmo SME, de caráter forte e inegavelmente racializado, que enquadra e desqualifica, clara e abertamente, significativos pertencimentos da diáspora negra coexistentes na referida escola municipal, quais sejam: as práticas musicais afrodiaspóricas do funk carioca.

Vale reforçar que estes procedimentos disciplinares também não são em nada exclusivos ao campo da Educação. Na política de pacificação da Secretaria de Segurança do Estado do Rio de Janeiro, o processo de implementação das chamadas Unidades de Polícia Pacificadora (UPP) vem sendo acompanhado, sistematicamente, pela proibição dos funks nas comunidades em pacificação. Cidade de Deus, localidade em que mora grande parte dos alunos da E. M. Compositor Luiz Gonzaga e que foi a segunda a ser ocupada por esta política da Secretaria de Segurança (a primeira localidade foi o morro Dona Marta, no bairro de Botafogo, zona sul da cidade, no ano de 2008), é um bom exemplo disso. Palco importante de diversas histórias e personagens do funk carioca, como Cidinho e Doca, Bonde do Tigrão, Bonde do Vinho, Bonde Faz Gostoso, Bonde das Panteras, Tati Quebra Barraco, Deize Tigrona, Pretos de Elite, Os Havaianos, assim como os famosos bailes do G.R.B.C. Coroado e do G.R.E.S. Mocidade Unidos de Jacarepaguá, dentre muitos outros, Cidade de Deus teve, em 2009, seus bailes e outras tantas práticas de funk (como escutar funk dentro da própria residência, conforme relatado por diversos alunos da escola e também noticiado por alguns jornais de grande circulação ${ }^{5}$ ) silenciadas pela sua recente UPP. Trata-se de uma proibição que se repetiu em, praticamente, todas as ocupaçóes subsequentes a esta e sendo sempre justificada, basicamente, pelo argumento de que as práticas musicais do funk carioca constituem um importante eixo financeiro e ideológico do tráfico de drogas e, consequentemente, da própria violência nessas localidades.

Foi justamente diante destes procedimentos capilarizados nos mais diferentes cotidianos da cidade que emergiu o chamado movimento de politização do funk carioca. Em linhas gerais, ele consiste em uma reação ao processo de criminalização de suas práticas musicais. Processo de criminalização, iniciando na década de 1990, basicamente, com a emersão e a demonização das práticas musicais do funk carioca na mídia corporativa da época, sobretudo dos bailes e dos chamados proibidóes. (HERSCHMAN, 1997, 2000) Passou por uma Comissão Parlamentar de Inquérito (instituída pela resolução no 182 de 1999 da Assembléia Legislativa do Estado do Rio de Janeiro), responsável por investigar as brigas nos bailes e as acusações de violência, apologia ao crime e ligação com o tráfico de drogas (ASSEMBLÉIA LEGISLATIVA DO RIO DE JANEIRO, 1999) e culminou, 
enfim, com a lei estadual no 3.410/2000, a qual passou a vincular, previamente, a realização de bailes funk à autorização da polícia. (RIO DE JANEIRO, 2000)

A morte do jornalista Tim Lopes, no ano de 2002, que ocorreu em meio a uma investigação jornalística sobre diversas denúncias de exploração sexual nos bailes funk organizados na Vila Cruzeiro, comunidade pertencente ao conjunto de favelas do Complexo do Alemão, uma das mais recentes, festejadas e cinematográficas pacificaçôes da Secretaria de Segurança do Estado do Rio de Janeiro e palco de novela chamada "Salve Jorge", de uma das mais importantes emissoras de televisão do Brasil, reforçou, inclusive, ainda mais esse forte movimento de criminalização.

Somente na década de 2000 que uma reação a esse enquadramento começou a ganhar mais força. Ao trazer à tona as fragmentaçóes, divisóes e, principalmente, as exploraçóes presentes na complexa rede de produção e comercialização do funk carioca, que estão diretamente relacionadas, como muito bem nos atenta Lopes, "com as relaçóes de poder que constituem o mercado fonográfico" (LOPES, 2011, p. 101), movimentos como Funk é Cultura, Funk de Raíz e APAFunk, tornaram cada vez mais evidente o perigo de qualquer tipo de generalização destas práticas musicais. A partir das alianças entre funkeiros, acadêmicos, intelectuais e políticos de esquerda, assim como da emersão de práticas musicais consideradas mais politizadas, como as chamadas Rodas de Funk esses movimentos possibilitaram, por um lado, "[...] uma forma de mobilização social em torno da reivindicação e da promoção de seus direitos [...]" e, por outro lado, uma resignificação da própria identidade funkeira, que "[...] deixou de ser vista como uma performance alienante e passou a ser compreendida como [...] uma resposta subalterna a formas de opressão e exploração [...].” (LOPES, 2011, p. 121)

Mas aquele menino narrado anteriormente que seguiu, de uma forma despreocupada e irônica, sua curiosa caminhada pelos corredores da E. M. Compositor Luiz Gonzaga (sobretudo após a repreensão em alto e bom som de uma professora) permanece bastante viva em minha memória. A meu ver, ele enuncia uma dimensão política das práticas musicais do funk carioca ainda mais ampla e complexa do que a que vem sendo configurada neste chamado movimento de politização. Uma dimensão política que não está, de forma alguma, apenas restrita às (muito importantes, certamente) negociaçóes e alianças entre funkeiros, intelectuais, acadêmicos e políticos de esquerda (LOPES, 2011), mas também (e tão importante quanto estas mesmas negociaçôes, alianças e pertencimentos) dispersa nas enunciaçóes dos mais diferentes cotidianos da cidade, envolvendo outras tantas negociaçóes, alianças e pertencimentos, porém de sujeitos anônimos e ordinários (CERTEAU, 1994), como é o caso, conforme pretendemos mostrar no decorrer dos próximos parágrafos, daqueles que habitam o dia a dia da referida escola municipal de ensino fundamental da cidade do Rio de Janeiro. 


\section{A prática de DJ no cotidiano de uma escola municipal carioca}

O que é cotidiano? Como é o cotidiano de nossa escola? Eis as duas perguntas a partir das quais iniciei meu trabalho de pesquisa com os alunos de seis turmas do segundo segmento do ensino fundamental da E. M. Compositor Luiz Gonzaga no ano de $2011 .^{7}$

Em relação à primeira pergunta, a noção de repetição, de reprodução foi predominante. A maioria das respostas girou em torno da ideia de rotina, daquilo que fazemos todos os dias. Quanto à segunda, foi destacado, basicamente, o que se repetia no dia a dia da escola, sobretudo na organização linear do tempo: entrada às $7 \mathrm{~h} 15 \mathrm{~min}$. da manhã, três tempos de aula, intervalo de $9 \mathrm{~h} 45 \mathrm{~min}$. as $10 \mathrm{~h} 05 \mathrm{~min} ., \mathrm{mais}$ dois tempos de aula e (finalmente, segundo os próprios alunos) saída as $11 \mathrm{~h} 45 \mathrm{~min}$. Somente após instigá-los com algumas problematizaçóes e brincadeiras é que, finalmente, começaram a comentar de forma mais à vontade (como se percebessem, aos poucos, que náo seriam criticados ou mesmo chamados à atenção) sobre outras práticas que também permeiam o cotidiano escolar (transversalizando esta linearidade), como conversar com os amigos, dormir, namorar, matar aula, ouvir música, dançar, atrapalhar os professores etc.

Com o desenrolar de nossas conversas, não foi difícil ver emergir, também, questionamentos à rotina da escola e algumas ideias de mudança: colocar o recreio dos menores ( $6^{\circ}$ e $7^{\circ}$ anos) em horário diferente dos maiores ( $8^{\circ}$ e $9^{\circ}$ anos); permitir a utilização do pátio externo da escola durante o recreio; colocar música no pátio interno da escola durante o recreio; promover mais passeios e festas. Dentre estas mais diversas ideias, percebemos que a sugestão de colocar música no pátio interno da escola durante os $20 \mathrm{~min}$. de recreio (uma prática, na verdade, já realizada por eles diariamente através de seus próprios aparelhos eletrônicos como mp3, mp4, celulares, dentre outros) era a que menos dependeria da direção (apenas de sua autorização) e muito mais da organização dos próprios alunos. Assim, e justamente por isso, começamos a desenvolvê-la.

Inicialmente, essa atividade que começamos a chamar de Música no Recreio e que, alguns meses mais tarde, ganharia, por parte dos próprios alunos, o título de Gonzagão Digital ${ }^{8}$, consistia apenas em um aparelho de som com um CD tocando algumas músicas gravadas pelos próprios alunos. Algo muito próximo ao que na década de 1960 ficou bastante conhecido como "orquestra invisível”. (ASSEF, 2003) Até que um dia, Gabriel (mais conhecido como Dentinho), então aluno da turma 1903 ( $9^{\circ}$ ano), considerada uma das piores turmas da escola pelo grande histórico de problemas disciplinares, de aprendizagem e de defasagem idade/ano, me abordou durante um desses recreios: "Professor, se eu trouxer o laptop do meu primo você me deixa tocar no recreio?”. Taí uma ideia 
que em momento algum tinha passado pela minha cabeça. E achei maravilhosa! Contudo, ao invés de contar com o laptop do primo de um aluno, resolvi, então, solicitar à direçáo um dos netbooks disponíveis em nossa escola para utilizarmos na realização da proposta. Baixamos algumas versóes gratuitas de softwares de DJ (como Virtual DJ sugerido pelos próprios alunos) e começamos a tocar "ao vivo", já na semana seguinte, durante os recreios das sextas-feiras.

Desde então, com seus celulares conectados a estes softwares gratuitos através de cabos USB, os alunos têm se inventado DJs mixando suas mais diferentes músicas na linearidade dos 20 minutos de recreio. Mixagens atravessadas por uma infinidade de scratches, loops, sons (como gritos, cantos e vinhetas previamente gravadas, como "Fala aí suvaco de grilo", seguida de uma ruidosa gargalhada), corpos (dançando, correndo, brincando, parados ou mesmo brigando no pátio interno da escola) e histórias (como a que está sendo narrada nestas linhas), dentre tantas outras enunciaçóes, inorganicamente combinadas, que (des)tecem aquele cotidiano escolar.

Organizar esta atividade de forma que praticamente todos os alunos do segundo segmento do ensino fundamental das turmas da manhã possam participar diretamente de sua realização não tem sido uma tarefa fácil. $O$ formato que chegamos até o momento, contudo, tem possibilitado sua realização, ainda que com muitos tropeços e, certamente, tensôes: a cada sexta-feira, uma turma fica responsável pela referida atividade e durante a semana que a antecede seus alunos negociam, no decorrer das próprias aulas de música, o repertório e os alunos-DJs responsáveis em tocá-las no tempoespaço do recreio.

Os pontos de negociação têm sido bastante diversos, o que tem possibilitado debates bastante férteis, apesar de, na grande maioria das vezes, serem bem discensuais. $\mathrm{O}$ primeiro deles tem girado em torno do celular. Na Gonzagão Digital, este equipamento aparece como a principal plataforma de registro musical. Trata-se de um acervo vivo, em permanente movimento, que na esteira de Castro, "[...] revela a intencionalidade de quem o produziu e, por outro lado, de quem o organizou e guardou, mesmo quando o arquivo parece ter sido deixado 'do jeito que estava', sem qualquer cuidado [...]." (CASTRO, 2005, p. 8) 9 Entre os movimentos permanentes de gravaçóes (e desgravaçóes) das mais diferentes músicas e vinhetas, este acervo (que muitas vezes chega a reunir mais de 500 arquivos, dependendo da capacidade do cartão de memória e do tamanho das músicas) circula por um circuto comunicativo (entre bolsos, mãos, ouvidos, computadores, internet, dentre outros temposespaços) que rasura e tensiona, de uma forma muito clara, os pressupostos que sustentam a lei municipal 4.734/2008 que proíbe sua presença nas salas de aula (como o transtorno à ministração de aulas e o desrespeito à autoridade do professor e a paciência dos alunos). ${ }^{10}$ 
Outro ponto de negociação tem girado em torno das letras das músicas, mais especificamente ao que tem sido comumente enquadrado como violência e pornografia. Para alguns alunos, estas letras são indiferentes; para outros, elas são parte constitutiva justamente das músicas mais interessantes e animadas; enquanto que outros tantos não se sentem absolutamente obrigados a ouví-los na escola: "quem quiser ouvir isso, ouve no baile e não na escola!", desabafou uma aluna do $7^{\circ}$ ano para toda sua turma. De qualquer forma, conforme nos atenta Lopes, trata-se de "[...] atos de fala que retratam os mais diversos aspectos do cotidiano [...]: as dificuldades do trabalhador, [a sexualidade] a violência policial e o chamado tráfico de drogas [...]”. (LOPES, 2011, p. 142) Certa vez, contudo, não consegui evitar: precisei pedir aos alunos-DJs que tirassem uma determinada música: "Hoje eu vou partir para essa missão", do MC Vitinho, em que o chamado "bonde do jacaré" era exaltado e a polícia, mais especificamente o BOPE (Batalhão de Operaçóes Especiais), depreciada. ${ }^{11}$

Até 2012, estes casos de proibidóes me deixaram em uma posição bastante tensa e desconfortável. Um bom exemplo disso foram as visitas de policiais da Unidade de Polícia Pacificadora (UPP) da Cidade de Deus à nossa escola para averiguar denúncias de moradores dos condomínios próximos sobre a suposta realização de bailes funks na escola. $\mathrm{Na}$ ocasiāo, a diretora esclareceu aos policiais que se tratava de uma proposta pedagógica, em consonância com o movimento de politização do funk carioca. Outro ponto de negociação tem girado em torno do processo de seleção das músicas. O critério da vontade coletiva, apontado inicialmente pelos próprios alunos como o critério (supostamente) mais democrático na escolha das músicas (a exemplo da democracia representativa em que vivemos atualmente), tem se mostrado muitas vezes insatisfatório e bastante tenso. Isso, porque muitos alunos têm se sentido fortemente injustiçados por nunca conseguirem ver suas opçóes musicais selecionadas. Em grande parte das vezes, são músicas rotuladas de pejorativas e discriminatórias, por esta mesma coletividade, como sendo música de "viado", de "corno", de "paraíba", de "macumbeiro", de "velho" etc. Conforme nos questiona Bhabha (2013, p. 62): "[...] poderão esses sujeitos divididos [...] serem representados em uma vontade coletiva em que ecoa claramente a herança iluminista de Gramsci e seu racionalismo?”. Enfim, como desabafou certa vez uma aluna do $9^{\circ}$. ano: "quem disse que a maioria sabe o que é realmente melhor para nós?”.

\section{A montagem do funk carioca como ampliação da prática de DJ}

Se a música pode ser entendida como um tempo acusticamente trabalhado (ARAÚJO, 1992a, 1992b, 2013), a prática da montagem do funk carioca 
consegue tornar ainda mais híbrida essa temporalidade. Ao que parece, a prática de montagem do funk carioca amplia de uma forma bastante significativa a prática musical de disc jockey. Além de suas tradicionais mixagens, scratches e loops - que desempenharam um importante papel, tanto na emersão das primeiras equipes de som na cidade do Rio de Janeiro, quanto no desenvolvimento do que o próprio funk carioca se tornou nos dias de hoje (VIANNA, 1988; ESSINGER, 2005; LOPES, 2011), como também na realização da Gonzagão Digital narrada anteriormente -, esta prática musical da diáspora negra realiza outras tantas disjunçóes (analógicas e, principalmente, digitais), tornando ainda mais polifônicas e dialógicas (BAKHTIN, 2010) a temporalidade linear daquilo que tem sido enunciado como sua principal máxima: a música não pode parar! Gilroy, na verdade, já havia muito bem ilustrado as disjunçóes temporais disto, que Certeau (1994) sem dúvida chamaria de uma "arte de fazer com".

Ao abordar o que chama de "arte negra na era digital", Gilroy (2001, p. 212) escreve o seguinte:

[...] instrumentos acústicos e elétricos são inorganicamente combinados com sintetizadores digitais, uma multiplicidade de sons encontrados; gritos típicos, fragmentos mordazes de discurso ou canto e amostra de gravaçóes anteriores - tanto vocais como instrumentais - cuja textualidade aberta é atacada em afirmaçôes brincalhonas do espírito insubordinado que amarra essa forma radical a uma importante definição de negritude.

“Jack Matador”, criada pelo DJ Mamut (da equipe de som Pipo's), se apresenta como um bom exemplo disto. Apontada por Essinger (2005) como a primeira montagem a fazer grande sucesso nos bailes cariocas na primeira metade da década de 1990 (abrindo caminho a muitas outras montagens que viriam depois), "Jack Matador" compreende mais de cinco minutos de uma imbricada trama de um irônico riso agudo com frases de um seriado de faroeste faladas e picotadas em uma voz empostada retirada de um vinil velho, com rótulo raspado, tudo estreitamente trançado sobre a base da música "808 Volt Mix” do DJ Battery Brain, base bastante utilizada nos funks cariocas desta mesma época (época, inclusive, que precedia a criminalização de suas práticas).

Outro exemplo que também pode ser citado é a montagem "Quem fecha com a CDD”, de DJ Fabrício da Bloco Velho Digital, uma das principais equipes de som da Cidade de Deus, segundo depoimentos dos alunos da referida escola municipal. Trata-se de outra imbricada trama, agora com um pouco mais de um minuto e meio, que se inicia com alguns sons de tiros, com a frase picotada "quem fecha com a CDD levanta a mão e faz: hu hu, rock and roll" atravessada por alguns anúncios, como "Só dá ele, DJ Fabrício!” e "Quer sacanagem?”, dentre outros. Tudo isso sobre a base rítimica chamada beat box usada e abusada pelos funks 
dos últimos anos. Uma montagem do ano de 2011, já bem antiga (na opinião destes mesmos alunos), porém ainda bastante tocada no pátio interno da escola municipal carioca, numa época em que esta prática musical já aparece bastante dispersa nos mais diferentes cotidianos da cidade. Aliás, a tecnologia digital se apresenta como uma das principais condições desta mesma dispersão. Segundo o próprio Essinger,

[...] com um computador mediamente equipado, qualquer um podia se transformar em produtor - era só ter um programa como o Sound Forge, para cortar e modificar os trechos musicais que seriam usados, e um outro como o Acid, para colá-los e, de peça em peça, fazer uma música. Que, uma vez pronta, podia ser rapidamente copiada num CD. Com o mesmo computador, qualquer um também se transformaria em DJ-em alguns bailes de 2004, o mouse e o teclado já eram usados para disparar as músicas de sucesso que iriam estufar as caixas de som. O resultado é que as possibilidades musicais do funk passaram a ser infinitas, sem limites [...]. (ESSINGER, 2005, p. 269) [Grifo do autor].

Enquanto parte expressiva da política cultural do Atlântico negro (GILROY, 2001), a prática de montagem do funk carioca compreende o que Gilroy chama de um circuito comunicativo. Um (curto-)circuito, cujas disjunçóes enunciam uma imbricada trama de náo apenas sons previamente gravados e inorganicamente combinados, mas também de corpos e histórias, dentre tantos outros enunciados que coabitam, tensionam e conflituam os mais diferentes cotidianos da cidade, dentre os quais, a escola municipal carioca de ensino fundamental em questão. Em outras palavras, enfim, a prática de montagem do funk carioca pode ser entendida como aquilo que Bhabha chama de uma "prática enunciativa" (BHABHA, 1998, p. 248), ou seja, uma negociação cujas enunciaçóes se mostram capazes de deslocar, escapar ou subverter qualquer pretensão ou ingenuidade de enquadrá-la em determinados limites temporais totalitários, dicotomizados e lineares (neocoloniais).

\section{Considerações finais}

A prática de montagem do funk carioca está presente no cotidiano da escola municipal carioca em questão: com professor, sem professor e apesar do professor! ${ }^{12}$ Trata-se de uma coexistência indelével e inalienável que náo se apresenta (de forma alguma) natural, espontânea ou mesmo alienada, mas sim atravessada por uma infinidade de tensôes e negociações. A Gonzagão Digital, foco principal do presente trabalho, compreende apenas algumas destas, ao lado de muitas outras que tecem o cotidiano escolar em questão, dentre as quais poderia citar a histórica 
e tradicional prática de alunos ouvirem música no pátio interno durante os 20 minutos de recreio, com seus mais diversos aparelhos digitais (a qual deu origem à própria Gonzagão Digital) e, principalmente, a permanência de celulares e demais equipamentos no cotidiano da escola apesar da lei municipal 4.734/2008 proibir sua presença nas salas de aula.

Mergulhada em uma estrutura de subalternização de alunos, professores e do próprio funk carioca, esta narrativa musical da diáspora negra - conforme tentamos evidenciar no decorrer do presente trabalho - abre diferentes e significativas possibilidades no deslocamento das relaçóes neocoloniais que tecem o sistema público de ensino da Prefeitura da Cidade do Rio de Janeiro ao tensionar, por exemplo, as questôes em torno da criminalização do funk carioca, da proibição do aparelho celular, da letra das músicas e do critério de seleção do repertório. Em seu agenciamento, na ambivalência das disjunçôes que atravessam a linearidade da máxima da narrativa de montagem do funk carioca (qual seja: a música não pode parar, já que toda sexta-feira tem que ter música no recreio!), alunos-DJs e professor-pesquisador não se apresentam apenas como simples reprodutores de determinadas habilidades, competências e procedimentos disciplinares, mas se (re) inventam, cotidianamente, como sujeitos, como protagonistas de tantos outros conhecimentos.

Por fim, a prática de montagem compreende uma narrativa musical que tem sido ignorada ou opacizada de uma forma bastante significativa no entendimento da própria dimensão política do funk carioca. Dimensão política, esta, que tem sido reduzida a alianças entre funkeiros, acadêmicos, intelectuais e políticos de esquerda no decorrer da década de 2000. (LOPES, 2011) A meu ver, parece que o funk carioca só recebe o título de movimento político (como o Movimento Funk é Cultura, o Movimento Funk de Raiz e a própria APAFunk) quando passa a jogar na cartilha da política hegemônica, ou seja, quando passa a jogar na esfera de suas relaçóes de produção e comercialização, e não na esfera dos usos cotidianos (onde, na verdade, ele nunca deixou de jogar). Nesse sentido, portanto, ignorar esta prática musical da diáspora negra neste importante movimento compreende uma limitação da própria noção política do funk carioca.

\section{Notas}

1. Na esteira proposta por Gilroy (2001), por diáspora negra compreende um circuito comunicativo "[...] que capacitou as populaçôes [negras] dispersas a conversar, interagir e mais recentemente até sincronizar significativos elementos de suas vidas culturais e sociais [...]”. (GILROY, 2001, p. 20)

2. Conforme será discutido mais adiante, a prática de montagem do funk carioca é entendida no presente trabalho como um princípio narrativo que amplia, significativamente, a própria prática de DJ.

3. Conforme nos esclarece Schmidt, “[...] no acercamento aos sentidos do contemporâneo, não se 
pode deixar de observar que, sob a superfície aparentemente óbvia das racionalizaçôes operadas pelo pensamento liberal em torno do igualitarismo, da democracia e da liberdade, a estrutura colonial ressurge em forma residual nas relaçóes neocoloniais da 'nova' ordem mundial, desencadeando guerras culturais - a do cânone, a dos valores, a dos direitos, a do acesso, entre tantas outras - que são travadas em múltiplos espaços, da academia [da escola] e da mídia aos movimentos sociais e políticas de estado, deixando abertas as fraturas da nacionalidade, da raça, do gênero, da classe, da etnicidade e, por conseguinte, deixando claro que as fronteiras se reconstituem e se renovam na geração de margens, exclusôes e fragmentação social. Por isso mesmo, a era das identidades não é coisa do passado, mas se atualiza de forma urgente e imperativa face às dificuldades para a reconstrução histórica do sujeito e da identidade não discriminatória em contextos minados por um arsenal de autoridade, seja ela de cráter racial, sexual, étnico ou geopolítico [...]”. (SCHMIDT, 2011, p. 15-16)

4. A Prefeitura da Cidade do Rio de Janeiro possui a maior rede pública de ensino da América Latina, com mais de 1.000 escolas divididas em 11 Coordenadorias Regionais de Educação.

5. Ver, por exemplo, Chegada de postos policiais pacificadores pôs fim a bailes funk em comunidades do Rio, disponível em http://noticias.r7.com/cidades/noticias/chegada-de-postos-policiais-pacificadorespos-fim-a-bailes-funk-em-comunidades-do-rio-20100317.html; Polícia vai proibir bailes funk em locais de maior violência no Rio, disponível em http://g1.globo.com/Noticias/Rio/0,,MUL12277755606,00-POLICIA+VAI+PROIBIR+BAILES+FUNK+EM+LOCAIS+DE+MAIOR+VIOLENCI $\mathrm{A}+\mathrm{NO}+\mathrm{RIO} \cdot \mathrm{html}$.

6. Frente à degradação dos bailes funks (prática musical que ficou fortemente associada à violência $\mathrm{e}$ à exploração sexual no decorrer da década de 1990) e dos proibidóes (prática musical que ficou fortemente associada à apologia ao tráfico de drogas) realizada principalmente pela mídia corporativa e pelo próprio Estado (HERSMANN, 1997, 2000), as Rodas de funk surgiram como uma forma de intervenção na (re)significação do funk carioca, colocando em debate as relaçóes de exploração, preconceito e discriminação que atravessam suas mais diversas práticas musicais. (LOPES, 2011)

7. Observando mais especificamente os limites burocráticos da matrícula que possuo na referida escola municipal (um dos determinantes que estruturam minha pesquisa de doutorado), meu trabalho está circunscrito ao segundo segmento do ensino fundamental (ou seja, a turmas do $6^{\circ}$ ao $9^{\circ}$ ano), cuja grade de horário prevê apenas duas horas/aula semanais (cada uma com 50 minutos) para esta disciplina. Enquanto professor de 16 horas (das quais 12 horas/aula são destinadas à sala de aula e as horas/relógio restantes são destinadas a reuniôes e planejamentos), eu preciso assumir na escola, a cada ano letivo, exatamente seis turmas para conseguir cumprir por completo a carga horária de minha matrícula (caso contrário, preciso complementar a carga horária em outra escola). Assim, durante as manhãs de três dias da semana (as quais, desde o início da pesquisa, têm sido as de segunda-feira, quarta-feira e sexta-feira), eu leciono a disciplina Educação Musical na E. M. Compositor Luiz Gonzaga para cerca de 240 alunos (uma vez que cada turma possui 40 alunos, aproximadamente).

8. O termo Gonzagão já era uma referência bastante forte no cotidiano da própria escola ao campeonato de futebol entre as turmas do segundo segmento. Este campeonato acontece praticamente todos os anos (até aquele momento que cheguei à escola, parece que em apenas um ano não houve o referido campeonato, para grande decepçáo dos alunos). Assim, com o decorrer da pesquisa e, consequentemente, da atividade Música no Recreio ao longo dos anos de 2011 e 2012, esse termo Gonzagão foi sendo tomado de empréstimo para a equipe de som que aos poucos ganhava forma e vida.

9. Agradeço ao Prof. Dr. Samuel Araújo, coordenador do Laboratório de Etnomusicologia da Escola de Música da Universidade Federal do Rio de Janeiro, pelos férteis comentários a respeito desta forma de acervo.

10. Segundo o Projeto de Lei 1107 de 2007 da Vereadora Pastora Márcia Teixeira (PR) que deu origem a referida lei municipal, esta proibição justifica-se pelo seguinte motivo: "[...] tornou-se um transtorno à ministraçáo de aulas com o surgimento de celular e equipamento eletrônico. Quando não, um desrespeito à autoridade do professor e a paciência dos alunos que querem aprender, pois, a utilização de tais equipamentos, causa a desconcentração e inibe a memorização dos demais alunos. 
Por este motivo e motivada pela grande maioria dos incomodados apresento esta proposta de lei para a apreciação dos senhores vereadores [...]". (TEIXEIRA, 2007, p. 2)

11. "Hoje eu vou partir pra essa missão, alex lhuto encomendou, hornet doblô um astra e um corolla, pombinho emprestou fuzil várias pistolas, pra nós sair de fuga e ficar tranquiláo, mas se tiver herói nós deixa fudido porque é melhor perder se arrancar complica não adianta escapar ligar pro seu celular tú quer adrenalina? eu sei que eu sou bandido, 157 artigo 12 profissão perigo! Formiguinha na laje, santana na rua ca-cadinho metendo bronca os policias sabem disso. Caralho não fode caralho não fode, bonde do jacaré mata polícia da bope(2x)" Disponível em: <http://www.letras.com. $\mathrm{br} / \#$ !mc-vitinho/hoje-eu-vou-partir-pra-essa-missao>.

12. Na escola em questão, há um professor que, praticamente, todas as vezes em que éramos notificados sobre as novas orientações ou determinaçôes de CRE ou mesmo da própria SME, o que muitas vezes resultava em mais burocracias e prazos ao já táo conturbado trabalho dos professores, ele se virava para mim e, com um ar um tanto irônico, dizia mais ou menos o seguinte: "Zé Carlos, não se preocupe com isso. $\mathrm{O}$ serviço público anda: com o servidor, sem o servidor e apesar do servidor!". Este professor sempre procurava esclarecer, inclusive, que esse dito era muito falado entre os seus colegas de profissáo quando, antes de ingressar na carreira de magistério, trabalhava como engenheiro no período da ditadura militar em uma empresa privada que prestava serviços ao antigo Departamento Nacional de Estradas e Rodagens. Guardando as particularidades que envolvem este suposto "andar do serviço público", e não conseguindo ignorar a recente obrigatoriedade da música no currículo da Educaçáo Básica (determinada pela lei federal 11.769/2008), a apropriaçáo desse dito me possibilita esta pequena afirmação que, também, no mínimo de forma provocativa, tem se apresentado como pano de fundo para o desenrolar de minhas próprias práticas pedagógicas na referida escola e, consequentemente, do presente trabalho de pesquisa.

\section{Referências}

ARAÚJO, S. Acoustic labor in the timing of everyday life; a social history of samba in Rio de Janeiro (1917-1980). 1992. Tese de Doutorado em Etnomusicologia. Universidade de Illinois em Urbana-Champaign, EUA, 1992a.

. Descolonização e discurso: notas sobre o tempo, o poder e a noção de música. Revista Brasileira de Música, 20, 1992b, p.7-14.

. Entre muros, grades e blindados; trabalho acústico e práxis sonora na sociedade pós-industrial. Oído Pensante, vol 1, no 1. 2013. Disponível em: <http://ppct.caicyt.gov. ar/index.php/oidopensante/article/view/2199/1979>.

ASSEF, C. Todo DJ já sambou: a história do disc-jóquei no Brasil. São Paulo: Conrad Editora do Brasil, 2003.

BHABHA, H. O local da cultura. Belo Horizonte: UFMG, 1998.

. O bazar global e o clube dos cavalheiros ingleses. Rio de Janeiro: Rocco, 2011, p. $13-61$.

BAKHTIN, M. Problemas da poética de Dostoiévski. Tradução e prefácio de Paulo Bezerra. 5. ed. Rio de Janeiro: Forense Universitária, 2010. 
CASTRO, C. A trajetória de um arquivo histórico: reflexões a partir da documentação do Conselho de Fiscalização das Expediçóes Artísticas e Científicas no Brasil. Estudos Históricos, n 36, Rio de Janeiro, FGV, 2005.

CERTEAU, M. A invenção do cotidiano. 1. Artes de fazer. Tradução de Ephraim Ferreira Alves. Petrópolis: Vozes, 1994.

CIDADE DE DEUS. Direção: Fernando Meirelles. Produção: Andrea Barata Ribeiro e Maurício Andrade Ramos. Roteiro: Bráulio Mantovani. Rio de Janeiro: O2 Filmes, Globo Filmes, StudioCanal Wild Bunch, 2002. 1 DVD (130 min).

EBOLI, M. P. Educação corporativa no Brasil - mitos e verdades. São Paulo: Ed. Gente, 2004.

ESSINGER, S. Batidão, uma história do funk. Rio de Janeiro: Ed. Record, 2005.

GENTILI, P. Adeus à escola pública - a desordem neoliberal, a violência do mercado e o destino da educação das maiorias. In: GENTILI, P. (Org.). Pedagogia da exclusão. Petrópolis: Vozes, 1995.

GILROY, P. O Atlântico Negro: modernidade e dupla consciência. Tradução de Cid Knipel Moreira. São Paulo: Ed. 34, Rio de Janeiro: Universidade Cândido Mendes, Centro de Estudos Afro-Asiáticos, 2001.

HERSCHMANN, M. (Org.). Abalando os anos 90 - Funk \& Hip-Hop: globalização, violência e estilo cultural. Rio de Janeiro, Rocco: 1997. . O Funk e o Hip-Hop invadem a cena. Rio de Janeiro: UFRJ, 2000.

LINS, P. Cidade de Deus. Rio de Janeiro: Companhia das Letras, 1997.

LOPES, A. C. Funk-se quem quiser - no batidão negro da cidade carioca. Rio de Janeiro: Bom Texto, FAPERJ, 2011.

PASSOS, M. C. P. Reflexiones en torno a la experiencia de encuentro como metodología de investigación. In: IRAZOQUI, Y. del R. R. (Org.). Entre nosotros y los otros - experiencias metodológicas de investigaciones con niños sobre la comunicación y la vida social. Chiapas, México: Consejo de Ciencia y Tecnología del Estado de Chiapas, 2012.

RIO DE JANEIRO. ASSEMBLEIA LEGISLATIVA DO ESTADO DO RIO DE JANEIRO. Lei n. 3.410, de 29 de maio de 2000. Dispóe sobre a realização de bailes tipo funk no território do Estado do Rio de Janeiro e dá outras providências. Diário Oficial do Estado do Rio de Janeiro, 30 de maio de 2000.

Resolução n. 182, de 1999. Cria Comissão Parlamentar de Inquérito para investigar os bailes funk. Diário Oficial do Estado do Rio de Janeiro, 04 de novembro de 1999.

SCHMIDT, R. T. O pensamento-compromisso de Homi Bhabha: notas para uma introdução. In: BHABHA, H. O bazar global e o clube dos cavalheiros ingleses. Rio de Janeiro: Rocco, 2011, p. 13-61.

TEIXEIRA JR., J. C. Multiterritorialidade no espaçotempo escolar. Revista Teias, v. 12, n. 26, set-dez de 2011, p. 181-188. 
TEIXEIRA JR., J. C. E aí professor, o senhor não vai entrar na roda não? In: ENCONTRO NACIONAL DE DIDÁTICA E PRÁTICA DE ENSINO. 16., 2012, Campinas. Anais... Campinas: Faculdade de Educação, UNICAMP, 2012a.

. Isso aqui é meu futuro, professor!. In: CONGRESSO INTERNACIONAL COTIDIANO - DIÁLOGOS SOBRE DIÁlOGOS. 4., 2012, Niterói. Anais... Niterói: Faculdade de Educação, UFF, 2012b.

TEIXEIRA, M. Projeto de Lei 1.107. Rio de Janeiro: Câmara dos Vereadores, 2007.

VIANNA, H. O Baile Funk Carioca: Festas e Estilos de Vida Metropolitanos. 1987. Dissertação de Mestrado em Antropologia Social. Programa de Pós-Graduação em Antropologia Social, Museu Nacional/UFRJ, 1987.

Recebido em 31 de outubro de 2014.

Aprovado em 26 de maio de 2015.

DOI: http://dx.doi.org/10.1590/ES0101-73302015121367 